\title{
A framework for contributing case studies of child injury prevention programs (or a painless way to extract descriptions of child injury prevention programs)
}

ISCAIP shares the journal's determination to serve as a vehicle for disseminating a wide variety of information about the prevention of injuries. As previous ISCAIP columns have noted, we intend to do so by various means including the Internet! But a much more direct method is through the pages of Injury Prevention. Accordingly, this column is intended to assist those responsible for programs or projects to write about them in a reasonably painless manner. In this way we hope to encourage many of you to contribute these reports to future issues so that others can benefit from your experience.

Examples of promising programs and strategies to prevent injury and violence among children and youth are greatly needed by local and state agency staff in both the private and public sectors. ${ }^{1}$ Such case studies can serve as implementation models and training tools for a variety of practitioners, researchers, and policy makers.

Any prevention effort, whether successful or not, yields abundant lessons for other people or programs. Unfortunately, most journal articles focus on the methods employed in the design of research and evaluation studies with positive outcomes. Too often, the programmatic details of importance to practitioners are sacrificed. Negative findings and mistakes to avoid seldom are publicized.

We would like Injury Prevention to paint a panoramic picture of the many local agencies carrying out prevention activities in diverse settings using diverse approaches. Such case examples do not necessarily need to describe separate distinct injury prevention programs. In fact, some of the best examples may illustrate how injury prevention has been integrated within existing agency activities devoted to broader goals, but have become part of their infrastructure alongside the delivery of routine services.

To keep you informed of these examples we need to hear from many local practitioners across the globe. We need to know what went right or what went wrong in your efforts to implement injury or violence prevention strategies in your setting. So how do we accomplish this? To make such reports as painless as possible I propose a framework to describe programs that the journal will publish. This framework is adapted from case studies published by the Children's Safety Network. ${ }^{2}$ Note that not all elements need to be included, but, as a rule, more is better!

\footnotetext{
(I) Name of program/project

a. Lead agency

b. Start/end dates

c. Target population

d. Audience reached

e. Funding sources

(II) Problem being addressed

a. How identified

b. Data sources used

c. Age specific/development considerations
}

\author{
d. Special risk factors \\ e. Other background information
}

(III) Program, its development and implementation

a. Objectives

b. Components/intervention strategies

c. Recruitment of target group

d. Specific roles for maternal and child health practitioners

e. Collaborators/multisectorial partners/coalitions

f. Training needed/provided

g. Adapting/tailoring the program to community needs

h. Sustaining the program/institutionalization

(IV) Evaluation methods and results

a. Formative

b. Process

c. Intermediate

d. Outcome

e. Limitations

(V) Resources needed

a. Staffing requirements

b. Fiscal requirements

c. Training requirements

d. Other (for example, donated time and materials)

(VI) Lessons learned

a. Prerequisite conditions

b. Barriers encountered and overcome (or not)

c. Facilitators

d. Additional opportunities

e. Recommendations/suggestions

(VII) Products/publications/materials/surveys developed/used

(VIII) Contact person
a. Address
b. Telephone
c. Fax
d. E-mail

We look forward to hearing about your program or having you encourage a colleague to write about his or her program. At the very least, provide us with a referral so that we may cajole a submission of a program description by others.

SUSAN SCAVO GALLAGHER

Center for Injury and Violence Prevention and Secretary, ISCAIP*

Children's Safety Network,

Education Development Center Inc,

55 Chapel Street, Newton,

MA 02158-1060, USA

1 Hayes M. Where have all the programmes gone? Injury Prevention 1995; 1: 213-4.

2 Children's Safety Network. Building safe communities: state and local strategies for preventing injury and violence. Arlington, VA: National Center for Education in Maternal and Child Health, 1994.

*Please note the correct ISCAIP address on the WWWW is: http://weber.u. washington.edu/ hiprc/iscaip.htm 